\title{
Impact of Gender Inequality in Socio-Economic Development: The Case of Women in Ethiopia
}

\author{
Tsegamariam Dula \\ Wolkite University, College of Agriculture and Natural Resource Management, \\ Department of Agricultural Economics
}

\begin{abstract}
The difference in power relations between men and women results in different gender roles social roles and socially appropriate characteristics and behaviors. The general objectives of the review were to review the impact of gender inequality on socio-economic development in Ethiopia. According to Kosher (2005), gender differences in power roles and right affect health fertility control survival and nutrition through women's access to health care lower control over their bodies and sexuality and restrictions in material and non-material reason. Experiences of rural poverty and vulnerability in Ethiopia are highly gendered. The UNDP standard gender indicators set the scene for any analysis of gendered social risks and vulnerabilities. The presence of rigid socially sanctioned gender roles in rural societies severely constrains women's choices regarding how they allocate their time among different paid and unpaid productive and household activities giving rise to the incidence of time poverty. Traditions and social norms often prevent women from gaining equitable access to and control of assets. Both women and men were participants of farming and other activities to sustain the life of the family in doing so they should have equal opportunity access to control over resources and benefits among them depending on the roles they perform.
\end{abstract}

Keywords: Gender inequality and socio-economic Development

DOI: $10.7176 / \mathrm{DCS} / 9-11-06$

Publication date: November $30^{\text {th }} 2019$

\section{Introduction}

The difference in power relations between men and women results in different gender roles social roles and socially appropriate characteristics and behaviors. They all are culture-specific (kabira and masinjila 1997) identified acting locus visualization and power among other things as components in the identification of different roles of men and women. Action refers to and community activities. Productive activities are those accomplished for income generation through production of goods and services. Reproductive are those accomplished for income generation through production of goods and services. Reproductive activities include child bearing and nursing as well as activities performed for maintenance of the family such as fetching water cooking collecting firewood etc. while community activities are those preformed for the welfare of the general community such as attending meetings. In most cultures, reproductive activities are defined to be roles of women whereas productive and community activities are heavily dominated by men.

Locus shows the environment in which men and women operate. It is important in identifying gender gaps particularly working at home or away from home. This is usually connected to freedom of movement and whether one has access to better income generating employment or not. In most societies women are the ones who are mostly working at home in the maintenance of the household or very close to home doing both household activities and small scale production and trading. By contrast it is invariably the men who work of men and women in such context is strongly associated with the level of autonomy and economic empowerment they have. Visualization is recognizing and being recognized due to certain activities and rewarded materially and also by privilege. Power is the ability to make decisions and force others to do what the power holder prescribes.

The deeply-rooted patriarchal culture prevalent in most societies attributes to men both at home and community level. Such persistent attribution of roles to either sex is referred to as gender stereotyping. Gender stereotyping and thereby gender inequality the inequality of opportunity right responsibility role and access to and control over resources is the result of socialization gender roles are not necessarily determined by sex status. Socialization is defined as "the process by which individuals acquire knowledge skills and dispositions that enable them to participate as more or less effective members of a group and the society" (Almaz, 1991:2). Thus, differential socialization induces differences in components of gender roles as mentioned above. The socially constructed division of labor results in different rewards statuses opportunities and roles (Hirut, 2004).

Different studies indicated the low status of women in developing countries in general and in Ethiopia in particular (Almaz 1991; Hirut 2004; Makaria 2005). Lack of access to productive resources such as land lack of access to educating employment opportunities basic health services and protection of basic human right low decision making violence and harmful traditional practices are some of the indicators of the socio-economic marginalization of women in the country. Such gender gap between men and women in socio-economic indicators has negative impact on the overall development of the county in general and on demographic and health outcomes individuals in particular. 
According to Kosher (2005), gender differences in power roles and right affect health fertility control survival and nutrition through women's access to health care lower control over their bodies and sexuality and restrictions in material and non-material reason.

\subsection{Objectives}

General Objectives

The general objectives of the seminar are to review the impact of gender inequality on socio-economic development in Ethiopia.

Specific objective

$>$ To review gender inequality in labor division and decision making pattern in the Ethiopian community.

$>$ To review gender inequality on socio-economic development of Ethiopia.

$>$ To review the major cause of gender inequality on socio-economic development of Ethiopia

\section{The Impact of Gender Inequality on Socio-Economic development}

\subsection{Basic concepts and definition}

Gender: - refers to socio-cultural perception of roles responsibilities and rights of human beings differentiated by sex and age such differences are determined by social cultural religious legal and economic norms on the base of which society organizes itself. It is characterized by social construed learned and dynamic (change over time).

Sex: refers to biological difference between men and women. It describes biological characteristics with which we born (is natural trait that categories a person as male or female)

Reproductive work: - is a work that support the welfare at family maintains it includes child care fetch water and fuel wood cooking washing nursing and other house hold tasks.

Productive work: - is a work which has monitory value it cores wide range of activities includes farming and business enterprise. It also includes marketable goods that have exchange value and consumable goods.

Community work: - is voluntary work (unpaid) that goes to want the producing of social status such as bulling school maintain produce and natural resource management.

Inequality: - it refers to unfair (unequal) treatment between groups of people in a society or in the community.

Access: - refers to the ability of an individual to get and to use a particular resource

Control: - it means power in both management and decision making that goes beyond simply using the resources.

Gender equality; It denotes women having legal access to economic political and cultural opportunities as men. It does not mean that women and men are the same but rather that their similarities and difference are recognized and equally valued (Abraham 2008).

Gender discrimination: It refers to systematic unfavorable treatments of individuals on the basis of their gender roles which dares them enjoying thesis right and assessing opportunities or resources (S. Anita 1995).

Gender analysis: It is systematic gathering and examination of information in order to identify understands and refers inequalities between women and men girls and boys based on gender roles a gender relation (Mace we Nicott.A 1994).

Gender Gap/disparities: There are socio-economic indicators at gender inequalities this include measure of employment education health ownership of property and income disparities. Gender gap results from inequality in decision power which leads to inequality in access to resources and by the differential treatment given to women and girls as compare to that given to men and boys. Gender discrimination exists as part of the social system and runs through all aspect of life and at different levels such as family level community level institutional level (Bogalech, 2000).

Gender inequality impose costs on productivity efficiency and economic progress by hindering the accumulating of human capital in the home and labor market and systematically excluding women or men form access to resource public services or productive activities gender discrimination diminished economy capacity to grown and to raise living standard (World Bank 2001).

Gendered risks poverty: We now turn to a brief overview of the key gendered economic and social risks facing men and women in Ethiopia. We first present an overview at the national level and then highlight the specificities of the locations of our research sites.

\subsubsection{Economic risks and vulnerabilities}

Experiences of rural poverty and vulnerability in Ethiopia are highly gendered. Women play a significant role in agricultural productivity (carrying out an estimated $40 \%$ to $60 \%$ of all agricultural labor (world Bank 2008a) but suffer from unequal access to resources and capacity building opportunities on a number of levels. Although data are not available at an individual level household level data highlight differences in the patterning of vulnerability among male and female headed households. While the 2004 WMS found no statistically significant difference in poverty between rural female headed and male headed household's female headed (54\% compared with $48 \%$ for male headed households) are more vulnerable to household level shocks (such as illness death of household 
member drought flood price shocks job loss, loss or death of livestock). This is at least in part because female headed households are more labor poor and thus more reliant on hired labor for land management which is expenses and have less direct access to land. So, have fewer available ex-ante coping mechanisms than their male counteracts (AFDB 2004). This greater vulnerability is in turn reflected in the higher dependence of female headed households on food aid (24.2\% for males compared with $43 \%$ for females) (ibid). moreover, the WMS found that while only $32 \%$ of male headed households reported the would struggle to raise 100 birr in a week to cope with a crisis $53 \%$ of female headed households maintained that they would be unable to do so. Moreover, women reported that they would be more likely to relay on loans or gifts from relatives whereas when were better able to depend on sale of livestock or crop (CSA, 2005). In the case of land tenure legislative changes (beginning with land reforms in March 1997) have brought about important changes in women's ability to secure land tenure in their own right.

\subsubsection{Social risks and vulnerability}

The UNDP standard gender indicators set the scene for any analysis of gendered social risks and vulnerabilities. On both of these measures Ethiopia scores poorly the country's ranking on the gender-related development index which measures gender disparities in basic human development is $132^{\text {nd }}$ out of 155 countries whereas the ranking on the gender empowerment measure which reveals the extent to which women take an active part in economic and political life is $85^{\text {th }}$ out of 109 countries (UNDP, 2009). In other words, there are significant differences in opportunities for human capital development between men and women. Literacy rates for rural women are just $19 \%$ compared with $43 \%$ for men and although the national aggregate gender gap appears to have closed for net primary school enrolment rates (in 2007 rates for both girls and boys stood at $45 \%$ (UNICEF, 2007). At secondary school level, there is still a notable gender gap in net enrolment ( $23 \%$ for girls vs. $30 \%$ for boys).

In the case of health women appear to suffer from poorer health with the prevalence of self-reported illness higher for women $(26 \%)$ than men (23\%) (ibid). In times of crisis women are likely to disproportionately absorb the impacts as evidenced by declining body mass index indicators (Ezemenari et al., 2002). High fertility levels (the total current fertility rate is $5.3 \%$ (UNICEF, 2007) are another important contributor to women's poor health status with the number of women receiving skilled attendants at birth at just $6 \%$ and the adjusted 2005 maternal mortality ration at 720 per 100,000 live births (ibid). additional health challenges include increasing rates of vulnerability to sexually transmitted disease (especially among young women in communities where polygamy is common practice and/or female circumcision increases risk of infection) including HIV/AIDS (AFDB, 2004).

These disparities in human capital development are shaped by gendered cultural norms and socialization processes which nekton (2007:13) summarizes as promoting the following broad gender division of labor. This cultural division of labor in turn shapes women's access to natural resources. (Desta et al 2006) argue that the degrading of natural resources affects women disproportionally since they are involved in the collection of firewood water for household consumption and feed for their livestock which requires travelling long distances.

This burden is especially problematic for women who earn additional income from selling firewood as they must either travel for to communal forests or risk rape and assault by entering forests at night gendered cultural norms are in turn reinforced through customary law which continue to exercise considerable influence despite formal legal reforms to advance gender equality. As law (2008) argues citing the World Bank while the constriction affirms the subordination of (customary) laws when people's girths are negative affected within the rural context customary practices have greater influence on gender relations than the formal system. Moreover, formal laws suffer from weak implementation and in many cases, provide contradictory or incomplete coverage in their protection for women existing law are often applied by judges in a manner that does not take account of women's rights.

Indeed, according to the organization of economic co-operation and development (OECD) social intuitions and gender index (SIGI) Ethiopia ranked $89^{\text {th }}$ of 102 countries in 2009. There has also been limited investment on the part of the government in women's legal literacy and sensitize programmed regarding women's rights. The discrimination that women face is often heightened in contexts where polygamous marriages are practiced planning and monitoring authorizes often overlook women who are married but whose husband may be living with other wives. As such they are often one identified as heads of households with implications in terms of distribution of land access to technology contact with extension workers and access to support services (AFDB, 2004). Gendered violence and harmful traditional practices constitute another manifestation of social risk and vulnerability faced by Ethiopian women.

A growing body of evidence suggests the violence against women and girls in Ethiopia is widespread including rape abduction (often to avoid dowry payments) early marriage (which limits girls, educations opportunities and negotiation power within the household) familial violence female genital mutilation (FGM) and trafficking (AFDB, 2004).

The Ethiopian demographic and health surveys (CSA et al 2005) also indicated that $75 \%$ of girls undergo FGM and that the average age of marriage is 16.1 years at national level and only 14.1 years in Amhara. The underlying causes of violence against women include among others women's low status and limited power their 
access to social and economic resources and limited legal protein (as discussed above). Moreover, victims are often afraid to report abuse and seek remedial action owing to prevailing cultural practices that condone such behavior fear of secondary victimization and low awareness and sensitivity of the community and law enforcement agencies regarding gender justice (MOWA 2009).

According to Caber (2000) notes the power is most effective when it restricts choice and hence agency without overtly appearing to do so.

In general women are found disadvantage than men as Oxfam (1998) and EARO (20000, observed the disadvantaged positions of women such as work load education nutrition and decision making power entitlement of earning etc. are point to be reassessed for any development intervention and this situation calls for the important of women through empowering them. IIRR (2000) observed that while men have different levels of access to lucrative careers and control over financial and other productive resource decision making power are vested on them. On top of this gender differential and inequalities in power relations benefit men only.

\subsubsection{The burden of domestic work and time poverty}

The presence of rigid socially sanctioned gender roles in rural societies severely constrains women's choices regarding how they allocate their time among different paid and unpaid productive and household activities giving rise to the incidence of time poverty. Culture religious beliefs and social norms are all factors which dictate that unpaid domestic and reproductive activities (such as water collection child care cooking and washing clothes) are the domain of female members of the household. This is precisely the situation in rural Africa as risers articulates in her recent study (2009) the effects of this domestic burden on women's economic opportunities are damaging and predictable but often neglected in policies aimed at increasing female participation in productive paid employment several aspects of this problem must be considered.

First the time burden of rural women's domestic unpaid work and the lack of substitutability of female labor in household work by men serve to limit women's choices with regards to accessing paid employment. Activities that are time intensive and physically arduous (e.g. loading and fetching indispensable household goods like water and fuel) are generally the domain of female household members with little help from males. Lack of infrastructure such as running water fuel-efficient stoves and electricity exacerbate women's unequal burden. Consequently, inequalities in the amount of time available to women and men to devote to paid employment ply a significant role in delivering the unequal outcomes previously outlined. Furthermore, even in the absence of cultural restrictions time poverty restricts women from taking advantage of employment opportunities which require travel or migration far from their rural homes.

Second time poverty may be a significant factor in men's dominance of riskier but also more lucrative types of work. The probability of success of a given venture is at least partly determined by the amount of time invested in it (that is the degree of risk can be endogenous).

Accordingly, the relative scarcity of time for women naturally leads to their having fewer opportunities than men to pursue such ventures (Serra, 2009). Third female time poverty contributes to unequal education outcomes which in turn hinder women from competing with men for more skilled better paid jobs. When men do not substitute for women in domestic labor female children are often called on to share this burden (boys are generally sent to the fields but they have fewer working hours). This combined with gender discrimination often results in lower school enrolments and attainments for girls and reinforces girl's weaker poison in the labor market. However, in some cases in particular in Latin American counties buses are withdrawn from school to work in agriculture and this worsens their educational levels relative to girls.

\subsubsection{Unequal access to assets}

Traditions and social norms often prevent women from gaining equitable access to and control of assets. The situation is capital described by Raj Kumaraa woman form the Etowah District in India (as cited in Kelkar 2009): women never control and assets. Land is passed on from father to son. Even jeweler that is gifted to a woman on her marriage is not give in to her it is kept by the parents-in-law if a man dies or remarries the woman is completely dependent on others for survival in many countries gender based inheritance and property gender based inheritance and property and land tenure laws restrict women's ability to own assets. Even in areas where women do have use rights gender biased social customs and norms often restrict their opportunities of gaining equal use of assets. Unequal access to assets undermines women's economic performance for a number of reasons. The study conducted by R. Pellizzoli (2009) in Box II-2 mentions however that access to assets is not enough if women do not have the revenant tolls to optimally utilize them (in this case study the lack of adequate resources to manage irrigation systems efficiently is critical).

\section{2 . Decision-making power}

\subsubsection{Power in gender relation}

Literatures reveal that power has different definitions in social and political theories. Feminists define power in terms of social relations of domination and subordination. Feminists understand power as power-over which is unjust and oppressive to those over whom it is exercised (Joan, 1979). Gender relation is a way in which culture 
in a society prescribes rights roles responsibilities and identities of women and men in relation to one another. Men hold superior position in households and communities and women are put to inferior position. In women's land rights issues power in gender relation implies men's higher access to and control over land and women's less access and low control over land. Low access to assets affects women's bargaining power.

Initially the very fact that women tend to bring fewer assets than men in to marriage is crucial. Assets and wealth (or lack thereof) influence women's status and bargaining power in the household as explained in a anonymous collective discussion in Bangladesh (Kelkar, Nathan and Johan 2004 as cited in Kelkar 2009): if you have no money there is no value for your choice. You are sitting in a corner like a little thief if you have assets everyone loves you. As well as having road implications for intra-household relations and the welfare of children women's lack of bargaining power in the household is reflected in decision regarding producing consumption and human capital formation. In addition research has indicated that lack of bargaining power is responsible for women having restricted access to information reparsing new technologies and innovations in agricultural production (such as for example new techniques of preventing livestock diseases). These effects combine to ensure that women's opportunities of participation in skilled.

\section{Access and control over the assets}

Women have had and still have the same right as men to obtain a land title provided there is a vacant plot in the irrigation scheme. In chokew the problem for women is not accessing land but the use that they make of it and the factors that influence this use and reduce women's livelihood possibilities lack of time and financial capacity to acquire new skills in farming to differential crops and to commercialize them the amount of productive and reproductive work that has to be carried out by women and the high rates of HIV and AIDS infection in the area. Factors that inhibit women from satisfying the conditions set out by the scheme management leading to the possibility of their losing the land or having their use of the land restricted in the future include unavailability of credit lack of marketing and processing facilities and limited control over price gender inequities in local and national decision making bodies unsuitability poor quality and unavailability of productive inputs and other difficulties such as the migration or young laborers to south Africa.

Return to rain-fed agriculture. Stressing the importance of access to irrigated land for women's livelihoods and for households' food security in rural areas the study suggests that notwithstanding land's potential for commercial agriculture the management of the irrigation scheme has to consider the social value of that land too. There is more to irrigated land than mere soil (Pellizzoli, 2009).

\section{Lack of access to assets and gender bias: a vicious circle}

Women's lack of access to assets acts as a self-perpetuating cycle which only serves to strengthen already existing gender biases in employment opportunities. Without assets to act as collateral it becomes more difficult for women to access credit to purchase property and productive inputs.

Initiatives such s the Garment Bank have been set up with the aim of alleviating this constraint also women's limited means of attaining the use of key productive assess such as land water and livestock minimizes their capacity to use what asset they do have access to in a productive way. This further undermines their opportunities of taking part in skilled productive activities. (The overall ability of women to utilize assets as productively as or more productively than men when given opportunities to do so should not be doubted as Vigneri and Holmes showed with their research on the Ghanaian cocoa sector referred to in section I). This is exactly the situation which is observed in Afghanistan as can be (Ashrafi, 2009).

\section{Access to land and other resources}

Resources are means and goods including those that are economic like household income productive like land equipment's agricultural inputs (including labor) and opportunity to leadership and decision-making information organization and time. Access to resource implies to the ability to use resources and/or benefits and to make shortterm decisions on these resources (Akuna Beatrice, 2004). Women's access to land had terms of use rights that imply getting opportunity to use and benefit from land. Access to land is a means to gain control over land.

\section{Control over land and other resources}

Control over resources implies the ability to use and even dispose a resource or benefit. Women's control over land means the women can access land (use it) can own land (can be legal title-holders) and can make decisions on selling or leasing out the land (Akunna Beatrice, 2004). Therefore, women's control over land implies that women get access to land and they make major decisions on land.

Women's control over land is realizing equality. Land use as an agricultural resource and its disposition. Decision-making related to land includes land use and improvements control of products harvested form land including incomes earned from sales of products and decisions on land transfer through bequeath inheritance sale or rent.

\subsubsection{Women in power and decision making}

Due to the various obstacles, the women have such as triple role violence against women lack of reducing etc. Their representation in leadership and decision making position has also been limited. Despite the government policy of equal opportunity for both men and women to participate in the democratization of the country women 
has not been adequately represented at all levels of decision-making positions. Out of 547 seats reserved for parliamentarians in 1995, it was only $15(2.74 \%)$ that was occupied by women. However, by the next round election an increasing trend of women's participation has been observed. During the 2000 house of people's representative election about $42(7.7 \%)$ of the candidates for parliamentary seats were women compared to $2.7 \%$ in 1995.

Although not satisfactory women participation in local authorities has also improved. With the introduction of a federal system of government in 1991 by devolution of decision making power and responsibilities to regional states an increasing trend of women participation in local authorizes have also been seen. During the 1995 general elected for regional council out of 1355 members 77(5.0\%) were women. This number increased both in terms of membership and number women in 2000 election. Thus, in the election held in 2000 for regional council while the number of members increased to 1647 there were $244(12.9 \%)$ women which has shun an increase by $10 \%$. At the lowest level of woreda council only $6.6 \%$ are women out of the 70,430 the 928,288-elected official. Further at the level of international representation among the 28 ambassadors that Ethiopia appointed at different mission abroad, only (14.3).

In the area of employment while the number of women in the Ethiopia civil service has been relatively small the senior positions are overwhelmingly held my men. According the federal civil service commission recent statistics revealed the fact that the overwhelming majority of women civil servants are concentrated in poisons such as secretary cleaner and the following statistical data presents the presence of women in the cabinet and house of people representative.

Major challenges

lack of gender and environment awareness of the society as a whole

law level of integrating gender issues in the environment concerns

$\rightarrow$ lack of human power working in the field of gender and environment issues

the slow pace of implementing the aforementioned strategies has been challenging due to lack of commitment among others

the already established women's affairs office in EPA at a federal level is under staffed

the establishment of women's affairs bureaus in the regional EPA's have not been fully realized

loose mechanism for collecting gender disaggregated data

\subsection{Poverty and gender}

Gender inequality the disempowered position of women and girls is a characteristic feature of poverty in Ethiopia. Ethiopian women are economically socially culturally and politically disadvantaged in the enjoyment of equal rights in accessing opportunities decision - making processes and basic resources/services. Macro-economic indicators of development for the country are consistently low for women. Based on gender related development benchmarks developed by UNDP Ethiopia has earned a total GDI rank of 134 with index value of 0.335 making it one of the least developed countries in terms of gender equality.

Moreover, micro-economic studies on the situation of households estimate that female headed households which constitute about one-out of five rural households $(22.1 \%)$ and nearly two out of five urban households $(38.8 \%)$ along with the youth and the elderly are sections of the Ethiopia society that are most affected by poverty. For instance, in Addis Ababa where these households constitute 37\% of all households about 52\% belongs to the low-income category.

Consumption and expenditure surveys have also found that male headed households in Addis Ababa earn more than $50 \%$ in excess of the earnings of female headed households. One reason for this low earning of female headed households is the low proportion of female heads of households that are employed (53.43\% compared to $71.17 \%$ for male heads of households). In addition to low earnings the breadwinner in a female headed household is required to assume family responsibilities and meet day to day needs forcing them to opt for less paid jobs often at home or in the informal sector.

Women within male headed households are also vulnerable to poverty since women in many parts of the country so not won property or have access to financial resource and are dependent on men husband's fathers' brothers and sons for support. Even if women participate in economic transactions and earn money the power of sending the money is expected to go to the man of the family particularly if the amount involved is a bigger sum.

\section{Conclusions and recommendation}

\subsection{Conclusion}

As discussed in the body of our seminar paper inequality which made women inferior than men in any aspects primarily based on socially constricted gender biased outlook which was the majority sources of traditionally created gender inequality between girls and boys seems only impossible to change but also the behavioral change of both men and women and the community as a whole was something that should get proper attention.

The review indicated that one of the major constraints of girls and women related with their economic status 
in the localities from lack of access to control over key resources. This again related with household and with I community which makes them development on men their economic contribution being invisible in the society. Generally in our research gender inequality mostly seen in areas with relation to division of labor livelihood activities social attitude towards girls and boy's education one of issues wherein apparent inequalities between male and female in observed in household related decision making respondents were asked to state the final decision maker with the aspect of hose hold related issue frequently the participants of men and women in majority aspects $\mathrm{f}$ decision making processes within household level

\section{Recommendation}

$\checkmark$ The concept of gender recognizes the difference in the roles responsibilities access to and control over resources and sphere of authority between women and men. Both women and men were participants of farming and other activities to sustain the life of the family in doing so they should have equal opportunity access to control over resources and benefits among them depending on the roles they perform.

\section{References}

[1]. Almaz E(1991). Perspectives on gender and development. In TshealiBerhane Selassie (ED). Gender issues in Ethiopia. Institute of Ethiopia. Institute of Ethiopia studies. Addis AbabaUniversity Addis Ababa.

[2]. Balk D (1994). Individual and community aspects of women's status and fertility in rural Bangladesh. Population studies 48(1):21-45.

[3]. Hirut T (2004). Violence against women in Ethiopia A strong case of civil society concern in Chowdhury, Wais A., and kahsaiWoldeGiorgis (Eds) civil society in Ethiopia reflections on realities and perspectives of Hope. African Asian studies promotion association.

[4]. Joshi ST (1999). Women and development the changing scenario. New Delhi Mittal publications.

[5]. Kabira WM Masinjila M (1997). ABC of gender analysis. Forum for African women educationalists Nairobi Kenya.

[6]. Kishor S (ed) (2005). A focus on gender collected papers on gender using DHS data Calverton Maryland USA ORC macro.

[7]. Mason KO (1986). The status of women conceptual and methodological issues in demographic studies sociological forum 1 (2) 284-300.

[8]. Mukuria A aboulfia C, Themme A (2005). The context of women's Health results from the demographic and health surveys 1994-2001. Comparative reports no 11 Calverton Maryland ORC macros.

[9]. Women's information center (2005). Training manual for gender planning ministry of community development gender and children Tanzania. 